\title{
El patrón hidrográfico de la cuenca del río Blanco: control tectónico y geomorfológico ${ }^{1}$
}

\author{
María Mardones², Julius Jara² y José Vargas 3
}

\begin{abstract}
RESUMEN
La geometría y dinámica de la red hidrográfica presentan gran sensibilidad en el corto periodo geológico, frente a variaciones tectónicas, climáticas y geomorfológicas. Se analiza y explica el patrón hidrográfico de la cuenca del río Blanco, particularmente las capturas y reorganización Postglaciar de la red. Para tal finalidad, se desarrolló un análisis morfométrico de tipo hortoniano en Imágenes de Radar de la Misión SRTM de la NASA (2000), con el Programa River Tools y ENVI y en la carta topográfica del I.G.M. a escala 1:50.000. El levantamiento geomorfológico se efectuó mediante fotointerpretación y reconocimiento en terreno. Dos dataciones radiométricas ${ }^{14} \mathrm{C}$ fueron obtenidas de sedimentos morrénicos y lacustres. Se concluye que el patrón hidrográfico actual del río Blanco y particularmente las capturas son de origen Holoceno y estarían relacionadas principalmente con factores tectónicos y con los procesos de deglaciación de la zona austral de Chile. Se consigna una edad aproximada de 2.000 años para la red hidrográfica actual del río Blanco.
\end{abstract}

Palabras clave: Captura hidrográfica, evolución de patrones de drenaje, control morfoclimático del drenaje, Holoceno, geomorfología fluvial.

\begin{abstract}
The geometry and dynamics of the hydrographic pattern in the Blanco River basin, display major changes in short periods of geologic time, as a response to tectonic, climatic and geomorphologic variations. Captures and Postglacial reorganization of the pattern, were characterized by morphometric hortonian type analysis of Radar Images from NASA SRTM Mission (2000), using the River Tools and ENVI programs, as well as 1:50.000 topographic maps from the I.G.M. The geomorphologic mapping was done by photo interpretation and field work. Two C14 radiogenic dating were obtains of morrenic and lacustrine sediments. The river captures and the present hydrographic pattern of the Blanco river were defined about 2.000 years ago, during the Holocene, mainly due to tectonic factors and desglaciación processes on the Austral zone of Chile.
\end{abstract}

Key words: Hydrographic capture, river patterns evolution, morphoclimatic control river system, Holocene, fluvial geomorphology.

\footnotetext{
1 Proyecto Fondecyt № 105.0576 "Efectos geoecológicos y ambientales de la dinámica hidrológica y geomorfológica de la cuenca del río Aysén". Apoyo del Centro de Investigación en Ecosistemas de la Patagonia (CIEP). Artículo recibido el 3 de marzo de 2007 y aceptado el 8 de septiembre de 2007.
}

\footnotetext{
2 Departamento de Ciencias de la Tierra, Facultad de Ciencias Químicas, Universidad de Concepción (Chile). E-mail: mmardone@udec.cl; jujara@udec.cl.

3 Departamento de Ingeniería Civil, Facultad de Ingeniería, Universidad de Concepción (Chile). Email: jvargas@udec.cl.
} 
Los ríos de montaña constituyen vías de evacuación de las aguas y de los sedimentos de regiones geomorfológicamente muy activas. Los patrones de drenaje se definen por el trazado en planta dibujado por el conjunto de cauces a escala regional (De Pedraza, 1996). La geometría y dinámica de este patrón presenta gran sensibilidad en el corto periodo geológico, frente a variaciones tectónicas, climáticas y geomorfológicas (Owens \& Slaymaker; 2004; Burbank \& Anderson, 2005). Estos mecanismos pueden explicar la morfometría y extensión de sus cuencas, los patrones hidrográficos actuales y la ocurrencia de capturas, estas últimas de gran relevancia como factores de perturbación ambiental.

Las capturas hidrográficas consisten en la desviación de una sección de un curso de agua por otro, facilitando la expansión de una cuenca hidrográfica a expensas de otra. Dos son los tipos más frecuentes de captura hidrográfica, según el mecanismo que las genera: por avulsión y por erosión. La primera, se relaciona con la elevación de un lecho fluvial por acumulación de aluviones, lo que produce una captura por descarga de este, en un valle vecino que se sitúa en una posición topográfica más baja. El segundo tipo de captura se forma por la erosión del interfluvio que separa dos valles vecinos. En su génesis pueden operar factores muy complejos de tipo tectónico, climático o eustático (Dorsey \& Roering, 2006; Chevillotte et al, 2005; Mather, 2000). Movimientos tectónicos rápidos de regiones montañosas se asocian a intensos procesos erosivos y a capturas de ríos (Burbank \& Anderson, 2005). El cambio de dirección de drenaje generalmente es marcado por un paleovalle, utilizado a partir del punto de captura por un cauce redireccionado, por codos de captura marcados por el ángulo hecho por las nuevas orientaciones de los cursos de agua $y$, finalmente, por rupturas de pendiente entre el valle captado y el nuevo nivel de base.

La estructura geológica puede tener una influencia notable sobre la organización del relieve, y a través de esta en el tamaño, forma y patrón hidrográfico de las cuencas, así como en la generación de capturas. Cuando la red fluvial se adapta a lineamientos de falla, diseña trazados angulados, paralelos y/o rectangulares (Burbank \& Anderson, 2005; Ministerio del Medio Ambiente, 1998). En relación a la morfología, la mayoría de las cuencas tiende a tener forma de pera, pero los controles geológicos conducen a numerosas desviaciones a partir de esta forma. Estas desviaciones pueden ser estimadas a partir del Índice de Forma (Horton, 1945), que expresa la razón entre el área y el cuadrado de la longitud máxima de la cuenca, el que puede variar para cuencas no deformadas por fallas, en rangos de 0,5 a 0,79.

Los procesos morfogenéticos fluviales se modifican rápidamente cuando se producen variaciones de pendiente. Movimientos tectónicos de solevantamiento son capaces de intensificar las actividades erosivas y de aluvionamiento y provocar cambios en la dirección del drenaje, especialmente por basculamiento de bloques. Burbank \& Anderson (2005) estiman para zonas tectónicamente activas, rangos medios de desplazamiento vertical < $1 \mathrm{~mm} / \mathrm{año}$, pero citan desplazamientos horizontales en fallas transcurrentes o de rumbo que pueden ser $>40$ $\mathrm{mm} / \mathrm{año}$. Aunque los movimientos verticales son pequeños, a la escala milenial pueden producir grandes perturbaciones geomorfológicas. Por otra parte, solevantamientos o subsidencias debido a fallas perpendiculares a un río modifican el gradiente y la sinuosidad del valle. Trazados anastomosados y meandriformes, versus trazados rectilíneos, podrían marcar la diferencia entre un sector solevantado y otro estable (Loget, 2005; Cox, 1994).

Whipple \& Tucker (1999) y Loget (2005) prueban que el drenaje de las grandes cuencas fluviales se orienta según la línea de mayor pendiente regional, determinada por las variaciones del nivel de base (mar o lagos). Estas variaciones, producidas por movimientos tectónicos o eustáticos, tienen como efecto la propagación de la erosión fluvial valle arriba. Secuencialmente a un descenso en el nivel de base, los ríos incrementan la erosión vertical, profundizan el cauce y se genera una ruptura de pendiente (knickpoint) en el curso inferior del perfil longitudinal. El punto de quiebre de la incisión puede remontar progresivamente el valle hasta recobrar el perfil de equilibrio, en rangos que pueden variar entre 0,001 a 0,1 m/año y en rangos 
mayores en regiones tectónicamente activas (Van Heijst \& Postma, 2001). Sin embargo, Loget (2005) demuestra que la rapidez de incisión de una red hidrográfica consecutiva a la caída de su nivel de base está fuertemente controlada por el área de la cuenca de drenaje; las grandes cuencas disponen de procesos más rápidos de incisión, lo que explicaría la ausencia de rupturas de pendiente (knickpoints) en el perfil longitudinal de estas.

Por otra parte, Molnar \& England (1990) relacionan los mayores rangos de incisión de valles montañosos a fines del Pleistoceno, con el solevantamiento glacioisostático o con el aumento de la descarga de los ríos y del potencial erosivo de la corriente. Paralelamente a estos procesos erosivos fluviales que se desarrollan como respuesta a la forzante climática, la ocurrencia de movimientos tectónicos (basculamientos) de gran escala puede inducir a la formación de capturas.
El río Blanco, afluente del río Aysén (XI Región de Aysén del General Carlos Ibáñez del Campo), tiene una cuenca de drenaje compleja, con escurrimiento permanente, alimentada por 5 subcuencas de variada morfometría y regímenes hidrológicos diferentes (Figura № 1 ). Todas las subcuencas vierten sus aguas hacia el NNW. La red fluvial presenta globalmente un trazado rectangular a subparalelo, que muestra claramente la influencia de la tectónica en la dirección del escurrimiento; pero además se observan profundos valles con huellas geomorfológicas que indican cambios importantes en la dirección del drenaje. Portezuelos con escasa elevación que fragmentan la línea divisoria de aguas entre dos subcuencas vecinas, paleovalles y codos de captura marcan el cambio de dirección de los cursos de agua en la cuenca del río Blanco.

La finalidad de este estudio es explicar, desde un punto de vista morfogenético y

Figura № 1

LOCALIZACIÓN DEL ÁREA DE ESTUDIO

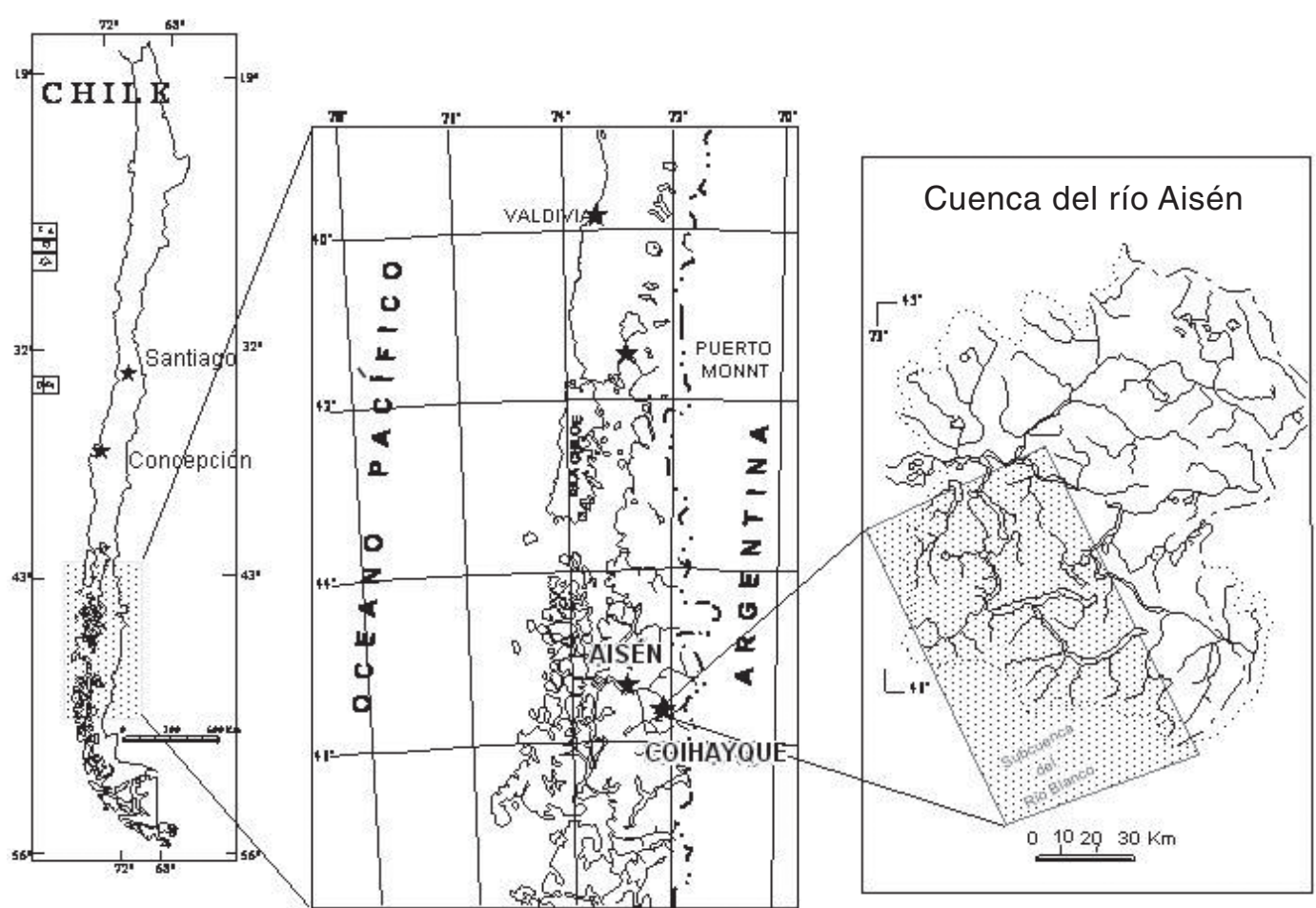

Fuente: Elaboración propia. 
morfotectónico, el actual patrón hidrográfico de la cuenca del río Blanco, particularmente las capturas y reorganización postglacial de la red fluvial.

\section{Localización y antecedentes generales del área de estudio}

La zona de estudio se emplaza en la cuenca del río Blanco, en el margen WSW de la cuenca del río Aysén (XI Región, Chile), entre $\operatorname{los} 45^{\circ} 25^{\prime}$ y los $46^{\circ} 02^{\prime}$ de latitud $\mathrm{S}$ y los $72^{\circ}$ y $72^{\circ} 55^{\prime}$ de longitud $W$, sección $\mathrm{N}$ de los Andes Patagónicos (Figura № 1). Este es un dominio tectónicamente activo debido a su localización al $\mathrm{N}$ del Punto Triple de Taitao, zona de contacto entre las placas Antártica, Nazca y Sudamericana, donde está siendo actualmente subductado un segmento activo de la Dorsal de Chile (Cembrano et al., 2002; Tebbens et al., 1997).

Su posición transicional entre la zona climática templada y el dominio austral con marcado acento antártico, le confieren una gran vulnerabilidad a los cambios climáticos globales (Moreno, 2004). Esto se expresa en las características físicas del relieve montañoso, abrupto y fragmentado por las glaciaciones pleistocénicas. Durante las glaciaciones cuaternarias, aquí se iniciaba el dominio de los grandes Campos de Hielo de América del Sur, elemento determinante en su actual configuración geográfica.

Las características geológicas del sector han sido investigadas por diversos autores (Niemeyer et al., 1984; Hervé et al., 1993; Hervé et al., 1995; Parada et al., 1996; De la Cruz et al., 2003). Desde el punto de vista tectónico, el área presenta una intensa deformación asociada al sistema de falla Liquiñe-Ofqui (Hervé, 1976; Hervé \& Thiele, 1987). Este sistema de fallas consiste en segmentos rectos de orientación NNW de centenares de kilómetros de largo, unidos por lineamientos en 'echelon' de dirección NE. Esta deformación se habría iniciado durante el Mioceno-Plioceno (Cembrano et al., 1996), siendo la tectónica reciente caracterizada tanto por la transcurrencia destral, como por altas tasas de alzamiento, durante el Holoceno. A nivel local, dominan fallas normales, de alto ángulo y rumbo NNW a NNE.

Como resultado de esta evolución tectónica, en la cuenca del río Blanco se observan dos unidades morfoestructurales de orientación N-S (Niemeyer et al., 1984): la Cordillera Principal al W, con altitudes superiores a $2.000 \mathrm{~m}$, conformada principalmente por rocas del Batolito Norpatagónico (dioritas, tonalitas, gabrodioritas y granitos del Cretácico inferior al Mioceno) y por un centro volcánico del Cenozoico superior: el volcán Hudson, situado al SW. Esta unidad morfoestructural se presenta profusamente erosionada por artesas y circos glaciales. Hacia el Este y a sotavento, se ubica la Precordillera con altitudes inferiores a $2.000 \mathrm{~m}$, estructurada por rocas metamórficas del $\mathrm{Pa}$ leozoico, que subyacen a una cobertura meso-cenozoica representada por rocas volcanoclásticas, volcánicas y sedimentarias, marinas y continentales. En ella se emplaza una cadena de lagos de origen glacial (lagos Elizalde, Rengifo, Zenteno, Caro, Atravesado, etc.). Esta limita hacia el E con la Zona Extraandina, de posición topográficamente más baja (400-700 m) y fuera del área de estudio (Figura № 2).

Tres tipos climáticos controlados por el relieve se distribuyen en franjas de orientación meridiana (Fuenzalida, 1966; Romero, 1985) al interior del área de estudio. De WE son los siguientes: clima marítimo templado frío y lluvioso, que afecta la sección occidental de la cuenca, con mínimas invernales inferiores a $0{ }^{\circ} \mathrm{C}$ y montos pluviométricos anuales de $3.000 \mathrm{~mm}$; clima frío de altura, en la sección centro-sur, donde la temperatura del mes más cálido es menor que $0{ }^{\circ} \mathrm{C}$ y clima trasandino, progresivamente $\operatorname{seco}(2.500$ a $400 \mathrm{~mm})$ y con fuertes oscilaciones térmicas anuales, hacia la Zona Extrandina oriental. La alta pluviometría y particularmente los altos índices nivométricos favoreció en el Pleistoceno la formación de vastos Campos de Hielo, los que fueron mejor alimentados en la sección sur y occidental más húmeda del área estudiada. Dichos Campos de Hielo ocuparon gran parte de la cuenca del río Blanco y dejaron su impronta en todo el modelado de la zona (Skarmeta, 1978). 
Actualmente, la superficie englaciada de la cuenca del río Blanco es pequeña $(17,93$ $\mathrm{km}^{2}$ ); escasos glaciares activos y residuales se observan en la sección $\mathrm{S}$ de la hoya, en las laderas de umbría y barlovento. La línea de equilibrio glacial se sitúa entre $1.050 \mathrm{~m}$ al $W$ y $1.400 \mathrm{~m}$ al $\mathrm{E}$.

Del análisis precedente surgieron las siguientes preguntas que guiaron esta investigación:

- ¿Por qué el drenaje de la cuenca del río Blanco se orienta en el presente hacia el sector montañoso del NW, si tiene una cuenca topográfica en el sector oriental (Zona Extraandina), que parece haber actuado como nivel de base de una parte del drenaje en el pasado reciente?
- ¿El patrón hidrográfico actual de la subcuenca del río Blanco y particularmente las numerosas capturas, tendrían alguna relación genética con la tectónica asociada a la Zona de Falla Liquiñe-Ofqui (ZFLO)?

- ¿Las características de los procesos de deglaciación de los Campos de Hielo podrían tener incidencia en la inversión del drenaje?

\section{Materiales y Métodos}

Para lograr el objetivo planteado, se recopiló información geológica y geográfica de la cuenca, se hizo un levantamiento geomorfológico, se estudió las característi-

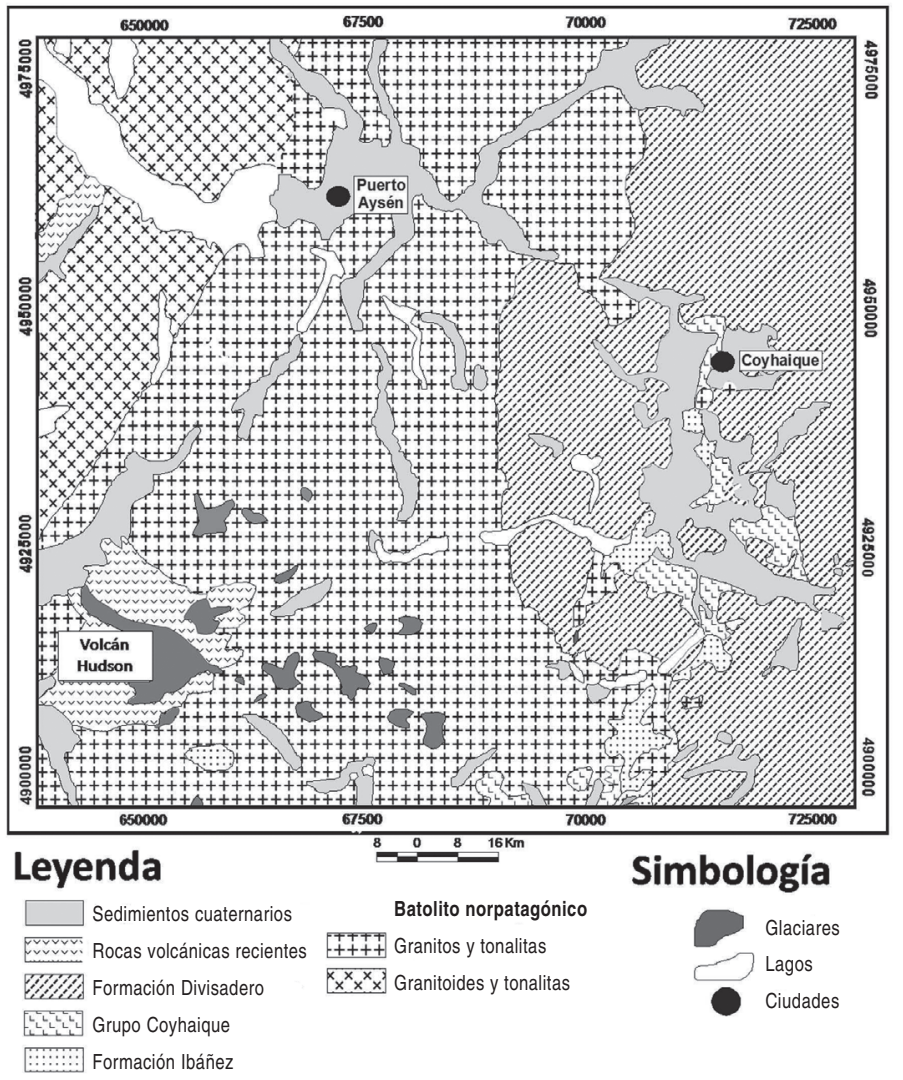

Fuente: Modificado de SERNAGEOMIN (2003). 
cas morfométricas de la red hidrográfica y la relación que esta tiene con los lineamientos tectónicos y con los proceso geomorfológicos registrados en los valles.

Las características morfológicas de la red y los lineamientos tectónicos fueron analizados cualitativa y cuantitativamente utilizando imágenes SRTM (Shuttle Radar Topography Misión) de la NASA (2000), las cuales fueron procesadas como imágenes raster utilizando el software ENVI 4.2, con el objetivo de definir topografía, pendientes y modelos sombreados. Los errores de lectura del radar fueron corregidos mediante un algoritmo proporcionado por el software 3DEM.

La confección de la roseta de rumbos se realizó con el software Stereonett; los datos de lineamientos fueron normalizados en relación a su largo, asignando un peso estadístico a cada uno. La roseta se confeccionó con pétalos de $6^{\circ}$ por clase, para representar más detalladamente la distribución de las tendencias de los lineamientos.

Para el estudio hidrográfico se aplicó el software RIVER TOOLS 2.4, definiendo en primer lugar los límites de la cuenca y al interior de esta los límites de las subcuencas. Sucesivas iteraciones de algoritmos incluidos en el programa permitieron definir la red de drenaje, la cual fue analizada de acuerdo a los parámetros morfométricos establecidos por Horton (1945) y Strahler (1964). Las estimaciones obtenidas mediante el software River Tools permitió la creación de gráficos y curvas hipsométricas. Paralelamente y para probar los resultados morfométricos obtenidos en forma automática, se desarrolló un análisis morfométrico hortoniano (Horton, 1945; Aparicio, 2003) con el uso de planímetro y curvímetro, en la carta topográfica a escala 1:50.000 del Instituto Geográfico Militar. Se estudiaron particularmente tres indicadores morfométricos hortonianos, por ser los que entregan mayor información acerca de los factores que controlan el patrón hidrográfico (Strahler, 1964). Ellos son:

a) Razón de bifurcación según orden de cauces

$$
R b_{u}=N_{u} / N_{(u+1)}
$$

Donde: $R b_{u}$ : razón de bifurcación para el orden u; $N_{u}$ : número de cauces de orden $u$; $N_{(u+1)}$ : número de cauces de orden inmediatamente superior.

b) Razón entre número de cauces y número de orden

$$
N_{u}=R_{b}^{(k-u)}
$$

Donde: $k$ es el orden del cauce principal $y$ los otros han sido definidos en a

c) Razón entre longitud de cauces y número de orden

$$
\overline{L_{u}}=\overline{L_{1}} \cdot R L^{(u-1)}
$$

Donde: $\overline{L_{u}}$ Longitud media de cauces de orden $\mathrm{u} ; \overline{L_{1}}$ : Longitud media de cauces de primer orden; RL: Relación de longitudes media.

La pendiente media de la cuenca fue determinada mediante el método clásico (Strahler, 1964), ponderando las bandas de altura de la cuenca por las curvas de nivel:

$$
S=H^{*} L_{i} / A
$$

Donde: $S$ : pendiente media de la cuenca; $H$ : diferencia de altura entre curvas de nivel; $L_{i}$ : longitud de las curvas de nivel en metros; $A$ : área de la cuenca.

El levantamiento geomorfológico preliminar se efectuó mediante fotointerpretación de fotos aéreas a escala 1:70.000, del vuelo GEOTEC-SAF (1997), cuyos resultados fueron vaciados a una carta base a escala $1: 100.000$. Dicha carta fue validada en 17 días de trabajo de campo. Se identificaron las capturas fluviales, y particularmente los relieves y procesos geomórficos que pudieran tener incidencia en la génesis de estas. Se comparó la orientación de los flujos con los lineamientos estructurales reconstituidos en este estudio y con aquellos identificados en la literatura geológica de la última década. El estudio detallado de la profundidad de las artesas glaciales y la altura de las paredes truncadas, estimadas a partir de las imágenes SRTM y de la carta topográfica, permitió evaluar la potencia de las lenguas glaciales durante la última fase glacial.

Dos dataciones radiométricas Standard AMS fueron obtenidas en el Laboratorio 
Beta Analitic Inc de Miami, Florida, EE.UU. La más antigua corresponde a un sedimento lacustre incluido en una morrena frontal, y la más joven a un depósito lacustre subyacente a un depósito morrénico. Estas dataciones han permitido establecer la edad en que se emplazó la red hidrográfica actual y la edad de las capturas, luego del retroceso de los glaciares.

\section{Resultados}

\section{El patrón hidrográfico de la cuenca del río Blanco}

La cuenca del río Blanco tiene una superficie de $2.970,76 \mathrm{~km}^{2}$; se han reconocido 5 subcuencas principales y varias subcuen- cas menores, al interior de las cuales se distribuyen 10 lagos de origen glaciar, con superficies que varían entre 26,7 y $2.000,0$ $\mathrm{km}^{2}$ (Cuadro № 1). La red contiene un total de 3.084 drenes de todos los órdenes, y de estos, un cierto porcentaje drena subterráneamente hacia los cursos principales. El trazado hidrográfico es anguloso a enrejado (Ministerio del Medio Ambiente, 1998), manifestándose claramente la influencia de la tectónica de falla que controla la dirección del sistema de drenaje de ríos y glaciares (Figura № 3 ).

Horton (1945) sugirió la clasificación de cauces de acuerdo al número de orden de un río, como una medida de la ramificación del cauce principal en una cuenca hidrográ-

Cuadro № 1

SUBCUENCAS DEL RÍO BLANCO

\begin{tabular}{|l|c|c|c|}
\hline \multicolumn{1}{|c|}{ Subcuencas mayores } & Área en km² & Orden & Lagos que incorpora \\
\hline $\begin{array}{l}\text { Elizalde } \\
\text { Lago Elizalde } \\
\text { Lago Caro } \\
\text { Lago El Desierto } \\
\text { Lago La Paloma } \\
\text { Lago Barroso } \\
\text { Lago Negro }\end{array}$ & 478,0 & 6 & Lago Atravesado \\
\hline $\begin{array}{l}\text { Riesco } \\
\text { Laguna Vera } \\
\text { Laguna Alta } \\
\text { Laguna Baja }\end{array}$ & 383,0 & 5 & Lago Riesco \\
\hline $\begin{array}{l}\text { Cajón Bravo } \\
\text { Quetro }\end{array}$ & 366,0 & 5 & Laguna Los Curas \\
\hline $\begin{array}{l}\text { Lago Zenteno } \\
\text { Laguna Rengifo o Dorita } \\
\text { Laguna El Plomo } \\
\text { Tres lagos sin nombre }\end{array}$ & 256,0 & 5 & \\
\hline $\begin{array}{l}\text { Bongo } \\
\text { Valle del río Blanco }\end{array}$ & $1.454,8$ & 5 & \\
\hline
\end{tabular}

Fuente: Elaboración propia. 
Figura № 3

LAS CAPTURAS: UBICACIÓN Y EVIDENCIAS GEOMORFOLÓGICAS. CUENCA DEL RÍO BLANCO, XI REGIÓN DE AYSÉN

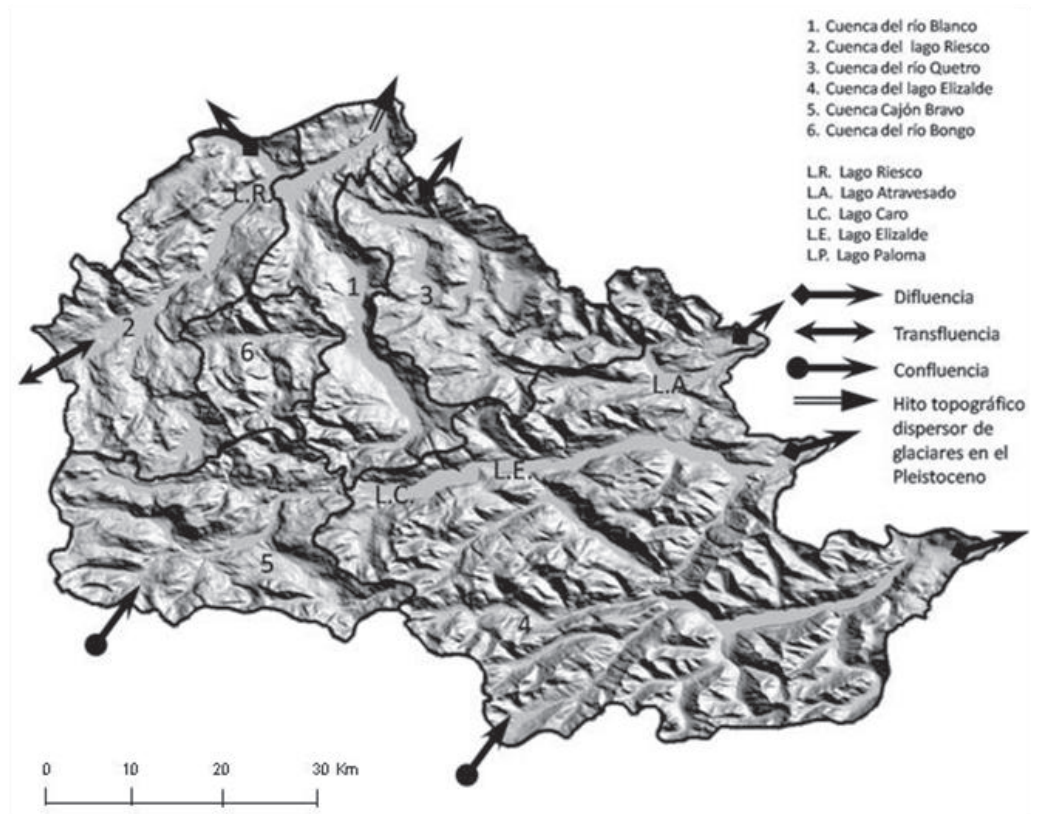

Fuente: Elaboración propia.

fica. El orden de los cauces se relaciona con la jerarquización de la cuenca; este permite comparar el grado de evolución de la cuenca y de sus subcuencas, si no existe interferencia tectónica. La cuenca del río Blanco tiene jerarquía 7, valor alto para su área, lo que podría explicarse por la presencia de un relieve fragmentado por la tectónica. Es una cuenca bien drenada que se ajusta a la razón entre número de cauces y orden propuesta por Horton (Figura № 4).

La razón de bifurcación $\left(R_{b}\right)$ definida por la relación entre el número de cauces de cualquier orden de magnitud y el número de cauces en el orden inferior tienden a ser constantes entre un orden y otro, si el clima y la litología no varían (Horton, 1945; Strahler, 1964). Los valores podrían oscilar entre 2 para sectores de planicies a 5 para sectores montañosos. Las razones de bifurcación calculadas para el sector investigado no se ajustan a la relación lineal propuesta por Horton, ya que estas varían entre 5,2 para ríos de orden 2 a 2 para ríos de orden 6 , observándose una marcada irregularidad entre los ríos de orden 4 y 5 (Figura № 5). Igualmente, al relacionar la superficie media de las cuencas con el número de orden, debiera teóricamente, según el mismo autor, observarse un crecimiento constante del área de las cuencas con su jerarquía. En el Cuadro № 2 se identifican irregularidades en este parámetro, especialmente en las máximas áreas registradas en las cuencas de orden 1. Ambas variaciones a las leyes de Horton podrían relacionarse con la fragmentación del relieve montañoso por la tectónica de falla.

Algunas perturbaciones en la morfometría de la red también fueron detectadas en la razón entre longitud de cauces y número de orden. La longitud media de los cauces debiera incrementarse en forma exponencial a medida que aumenta su orden (Strahler, 1964). En la cuenca del Blanco el ritmo de crecimiento es relativamente lineal entre los órdenes 1 al 5, pero los valores se desvían en los órdenes 6 y 7 , observándose una marcada variación de longitud entre el cauce principal y los cauces de órdenes menores 
(Figura № 6). Esto incide en la razón de longitudes, que representa la relación entre la longitud media de los cauces de un cierto orden y la longitud media de los cauces de orden menor, la que generalmente varía entre 1,5 a 3,5 (Singh, 1992). La relación de longitudes del curso principal se ha estimado en 4,3 , muy superior al valor que le precede (Cuadro № 2). La explicación podría estar en los mayores rangos de sinuosidad que tiene la red en el curso inferior $(\geq 2,7)$, relacionados con el trazado meandriforme que se desarrolla en la medida que la pendiente longitudinal del cauce disminuye.
La densidad media del drenaje permanente de la hoya del río Blanco es de 1,42 km/ $\mathrm{km}^{2}$, valor relativamente bajo que se asocia a la cobertura boscosa densa que cubre cerca del $50 \%$ de su superficie. Los mayores valores $\left(>12 \mathrm{~km} / \mathrm{km}^{2}\right)$ y la mayor variabilidad en la densidad del drenaje se registran en las subcuencas de órdenes 1 y 2.

La relación de elongación de Schumm (Strahler, 1964) corresponde al cociente entre el diámetro de un círculo con igual área a la cuenca analizada y la longitud máxima de la cuenca. Su valor depende del relieve;

Cuadro № 2

CARACTERÍSTICAS LINEALES Y DE ÁREA DE LA CUENCA DEL RÍO BLANCO

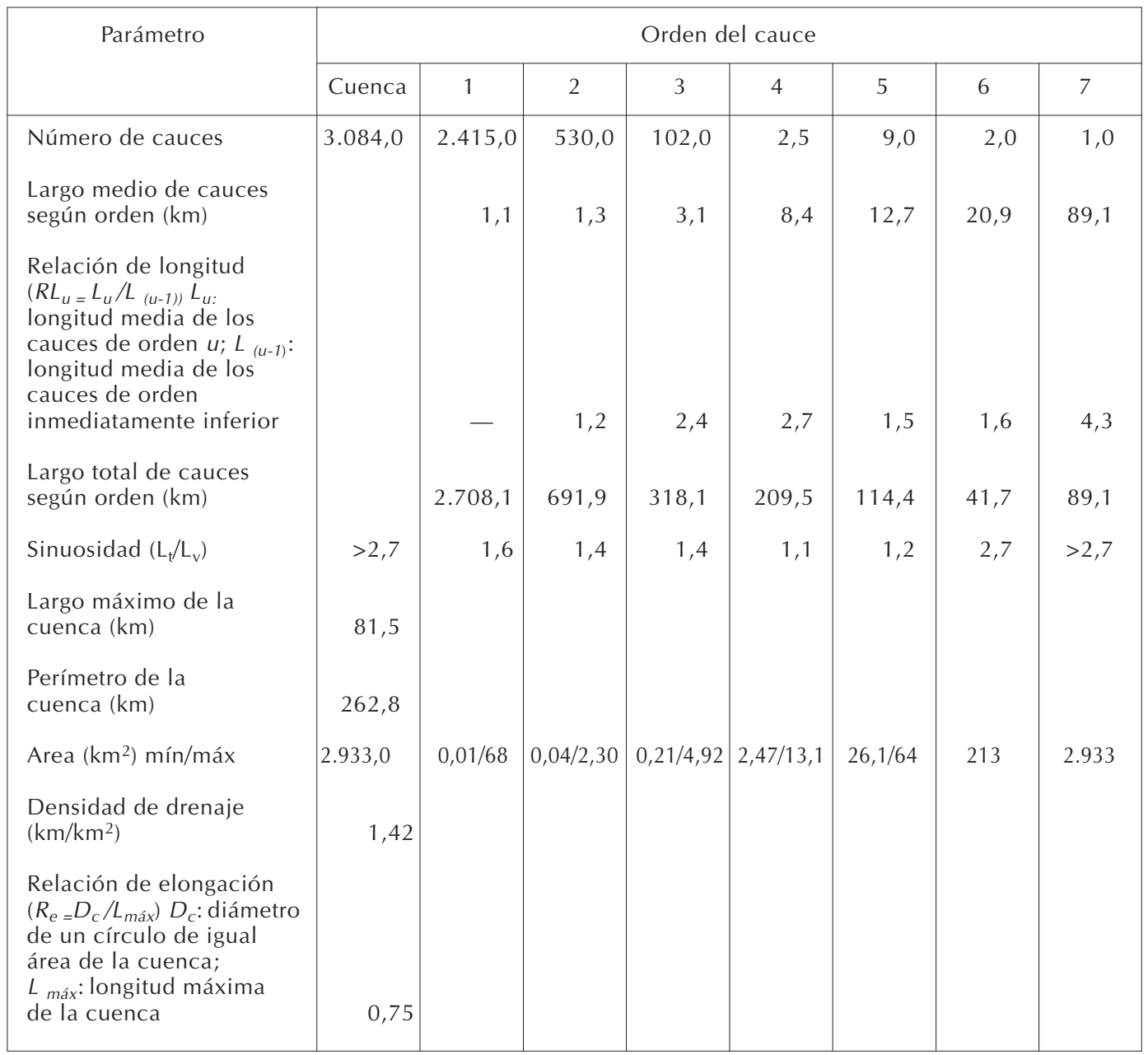

Fuente: Elaboración propia. 
Figura № 4

RAZÓN ENTRE NÚMERO DE CAUCES Y NÚMERO DE ORDEN PARA LA CUENCA DEL RÍO BLANCO

3
2
0
0
0
0
0
0
7
0
0
0
0
0
0
5
$\frac{1}{5}$
0
0
0
0
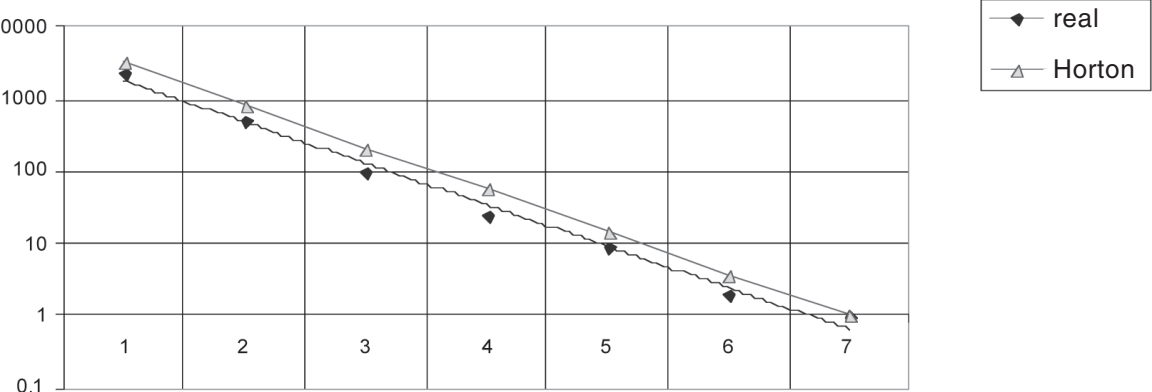

Fuente: Elaboración propia.

Orden de cauce

$y=6780 e^{-1,3198 x}$

$\mathrm{R}^{2}=0,9904$

Figura № 5

RAZÓN DE BIFURCACIÓN SEGÚN ORDEN DE CAUCE EN LA CUENCA DEL RÍO BLANCO

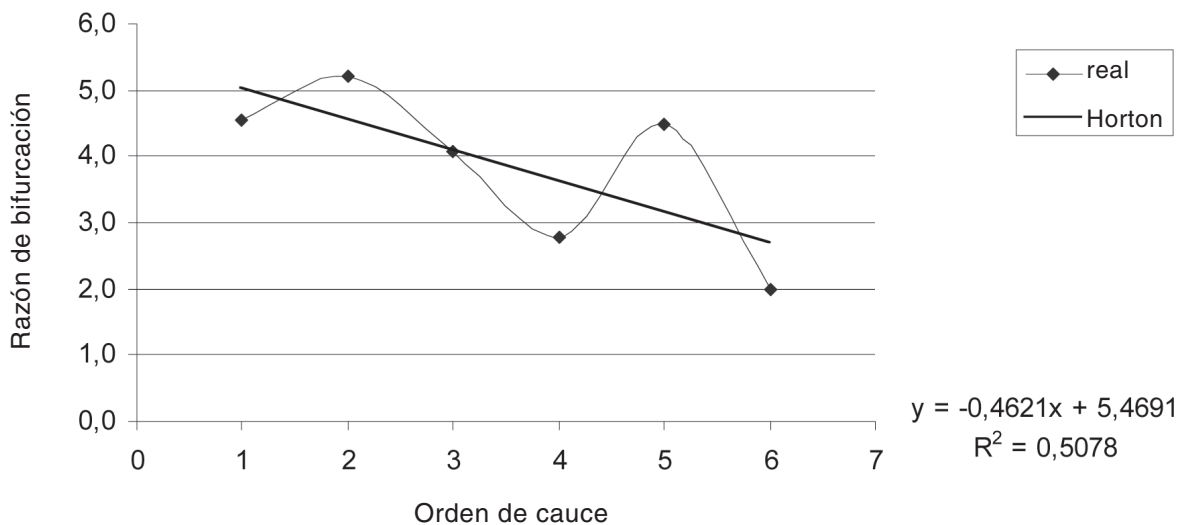

Fuente: Elaboración propia.

Figura № 6

RAZÓN LONGITUD DE CAUCES Y NÚMERO DE ORDEN PARA LA CUENCA DEL RÍO BLANCO

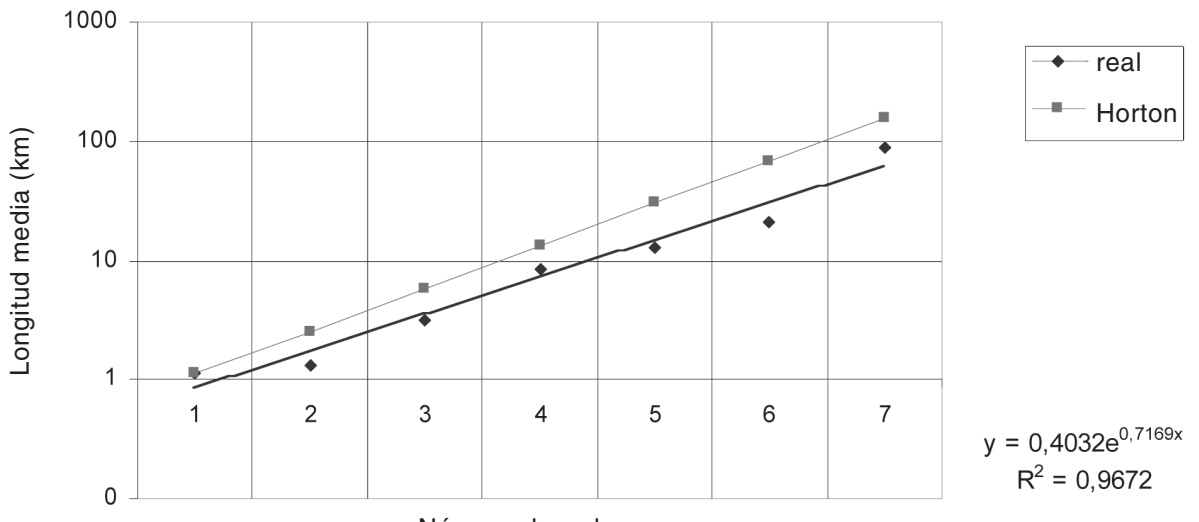

Fuente: Elaboración propia. 
para regiones planas, estos se aproximan a 1 y para cuencas con fuertes pendientes topográficas varían entre 0,6 y 0,8 . La relación de elongación en el río Blanco es de 0,75 (Cuadro № 2), lo que indica que la cuenca es de forma casi circular y con fuertes pendientes. La pendiente media de la cuenca ha sido estimada en $42,3 \%$.

\section{El relieve de la cuenca}

Las mayores altitudes se sitúan en la sección $\mathrm{S}$ del área de estudio, en la cordillera de Castillo (2.350 m.s.n.m.) y las menores, cercanas a $10 \mathrm{~m}$, en la confluencia del río Blanco con el río Aysén.

La curva hipsométrica es una forma de caracterizar el relieve; este parámetro permite evaluar el nivel de erosión y el grado de equilibrio dinámico de la cuenca (Strahler, 1964). En el río Blanco más del $50 \%$ del área drenada se sitúa sobre los $1.000 \mathrm{~m}$ y solo un $10 \%$ bajo los $200 \mathrm{~m}$ (Figura № 7). La convexidad de la curva y la pendiente media de la cuenca, superior a $42 \%$, estarían indicando un fuerte potencial erosivo; aunque la razón hipsométrica cercana a la unidad $(1,26)$, llevan a definirla teóricamente como una cuenca cercana al equilibrio morfogenético.

Datos más significativos aportan los perfiles longitudinales de los cauces y particularmente del cauce principal cuya pendiente media es de $6,2 \%$, en su curso medio e inferior. La Figura № 8 representa la pendiente media de distintos tramos que componen el cauce del río Blanco, desde la confluencia de los ríos La Paloma y Desague. Al contrario de lo que muestra la razón hipsométrica, este no es un perfil en equilibrio; presenta dos quiebres importantes: la pendiente cambia de $1,9 \%$ a $19,1 \%$ en la unión de la desembocadura del lago Caro con el río Cajón Bravo, este último un torrente de régimen glacionival de gran potencial erosivo. A 9 $\mathrm{km}$ al S de la unión de los ríos Blanco y Bongo, una nueva ruptura de pendiente (knickpoint) cuyo declive varía de 1 a $8,2 \%$ en el sector de Angostura, donde el río labra una estrecha garganta para salir al sector del lago Riesgo, finalizando su perfil con una inclinación de $0,2 \%$ en el curso inferior del río, donde este diseña un trazado meandriforme.

El índice de indentación de la cuenca (Strahler, 1964) que marca la diferencia entre las altitudes medias de las cimas y de los portezuelos, es relativamente alto (superior a 3). Especialmente en el sector oriental, la línea divisoria de agua es topográficamente rebajada por artesas glaciales que comunican la cuenca del río Blanco con la Zona Extrandina drenada por el río Simpson. Numerosos portezuelos originados por procesos de transfluencia glacial se observan también hacia el $\mathrm{N}$ y $\mathrm{W}$ de la hoya (Figura № 3 ).

Figura № 7

CURVA HIPSOMÉTRICA DE LA CUENCA DEL RÍO BLANCO

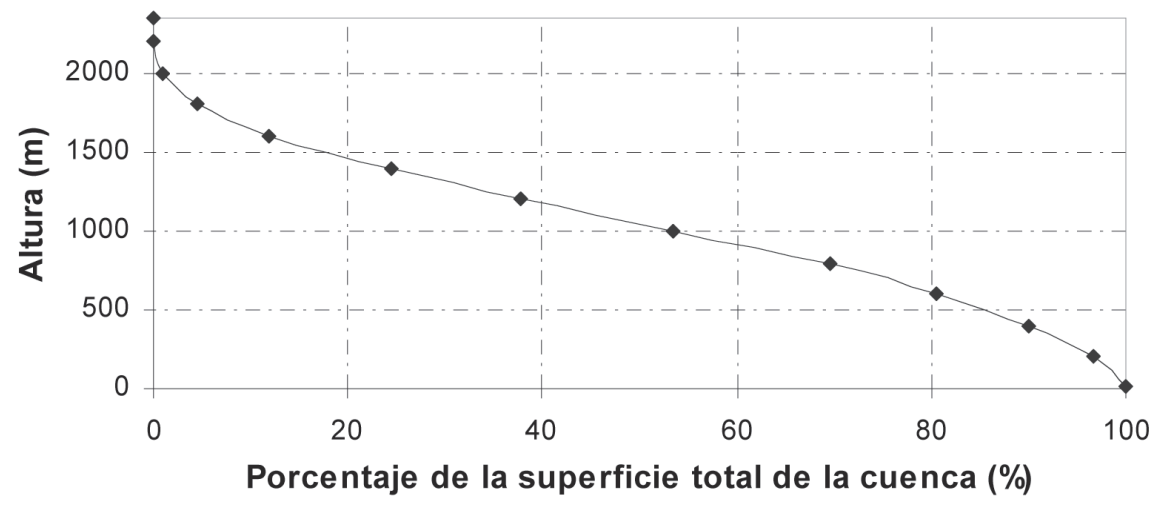

Fuente: Elaboración propia. 
Figura № 8

PERFIL LONGITUDINAL DEL CAUCE DEL RÍO BLANCO

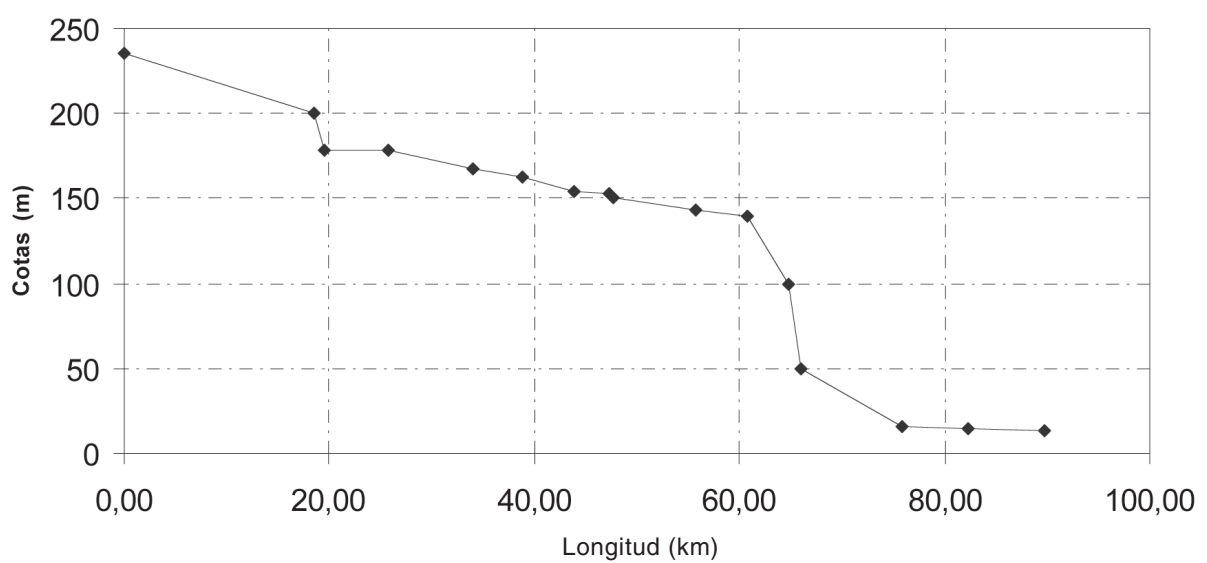

Fuente: Elaboración propia.

\section{Las capturas: ubicación y evidencias geomorfológicas}

Existen huellas morfológicas y topográficas claras de cambios en la dirección del escurrimiento fluvial y de la organización de las subcuencas fluviales que drenan hacia el río Blanco. La Figura № 3 muestra la actual organización del sistema hídrico; las flechas señalan la dirección divergente del drenaje durante el último periodo glaciar hacia la Zona Extraandina y hacia el océano Pacífico. Transfluencias y difluencias glaciales marcadas por portezuelos y artesas testimonian la presencia de un Campo de Hielo, lo que permite estimar la variación del área de la cuenca e identificar las disjunciones que esta ha experimentado en el Holoceno. Actualmente, el río Blanco actúa como nivel de base de 5 subcuencas principales: la de los ríos Quetro, Cajón Bravo y Bongo y las subcuencas de los lagos Riesco y Elizalde. Estos diseñan una intrincada red que drena hacia el NNW, la que se origina en los cerros Hudson, Castillo y en el sector precordillerano que limita con la Zona Extraandina al E.

La geomorfología muestra evidencias claras de capturas hidrográficas postglaciares. En la Figura № 9 un portezuelo originado por una transfluencia glacial, de aproximadamente $290 \mathrm{~m}$ de altitud, conecta el valle del río Huemules con la subcuenca del lago Riesco. Actualmente, los valles de los ríos Huemules y Cóndor tienen direcciones divergentes y drenan directamente hacia los fiordos Elefantes y Aysén, respectivamente, mientras que la subcuenca del Riesco lo hace hacia el río Aysén. Estos valles se encauzan en artesas glaciales de más de 500 $\mathrm{m}$ de profundidad. En el frente del lago Riesco se reconocen dos salidas: una hacia el $E$ que evacua las aguas del lago hacia el río Blanco; y otra hacia el WNW, marcada por una artesa glacial actualmente drenada por el estero El Salto, herencia de un antiguo emisario, cuyo drenaje fue bloqueado por una morrena frontal probablemente del Pleistoceno tardío, considerando su posición en la cuenca y la buena conservación de su forma y sedimentos (Figura № 10).

Más compleja es la organización del escurrimiento fluvial en la cuenca hidrográfica del lago Elizalde; esta presenta tres artesas topográficamente conectadas hacia el E con la Zona Extrandina. En el presente, se emplazan aquí los valles inundados por el lago Atravesado en la sección N, lago Elizalde en el eje central de la cuenca y lagos La Paloma y El Desierto en el margen S (Figura № $3)$, los que actualmente vierten sus aguas a través del río Desagüe y lago Caro hacia el valle del río Blanco, situado al W. En la Figura № 11 se grafican dos paleodirecciones en el drenaje de la artesa donde se sitúa el lago Atravesado; la primera conecta directa- 
Figura № 9

LA CAPTURA DEL RÍO CÓNDOR

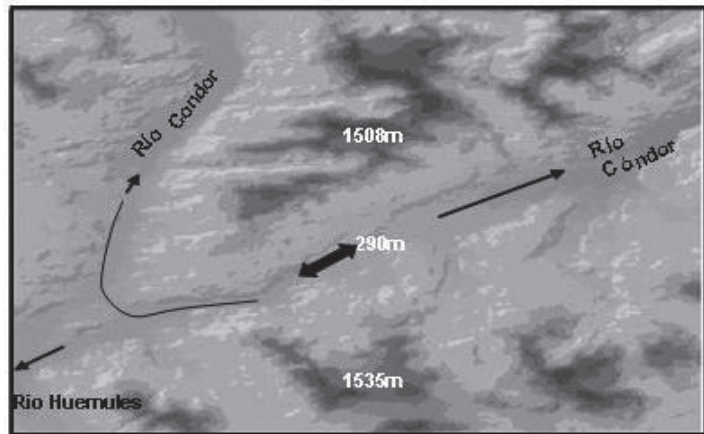

0

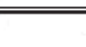

10

$5 \mathrm{~km}$

Fuente: Elaboración propia.

mente al E con la cuenca del río Simpson y el otro eje de escurrimiento se orienta al WNW, hacia el valle del río Quetro. Igual conexión con la Zona Extraandina se observa en la artesa glacial que aloja al lago La Paloma; las cordilleras Castillo y La Campa-

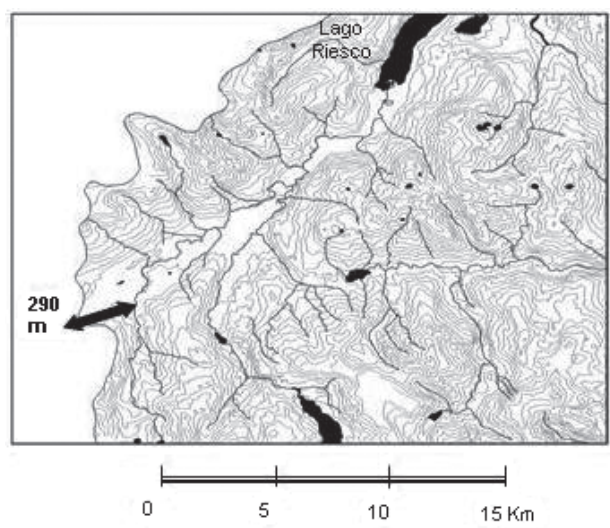

na $(\sim 2.000 \mathrm{~m}$ de altitud), zona de alimentación glacial de estos valles. Hoy, el drenaje se desarrolla hacia el NNW, discurriendo a través de estrechas artesas glaciales inscritas en la cordillera La Campana y cerros Los Cóndores (>1.800 m).

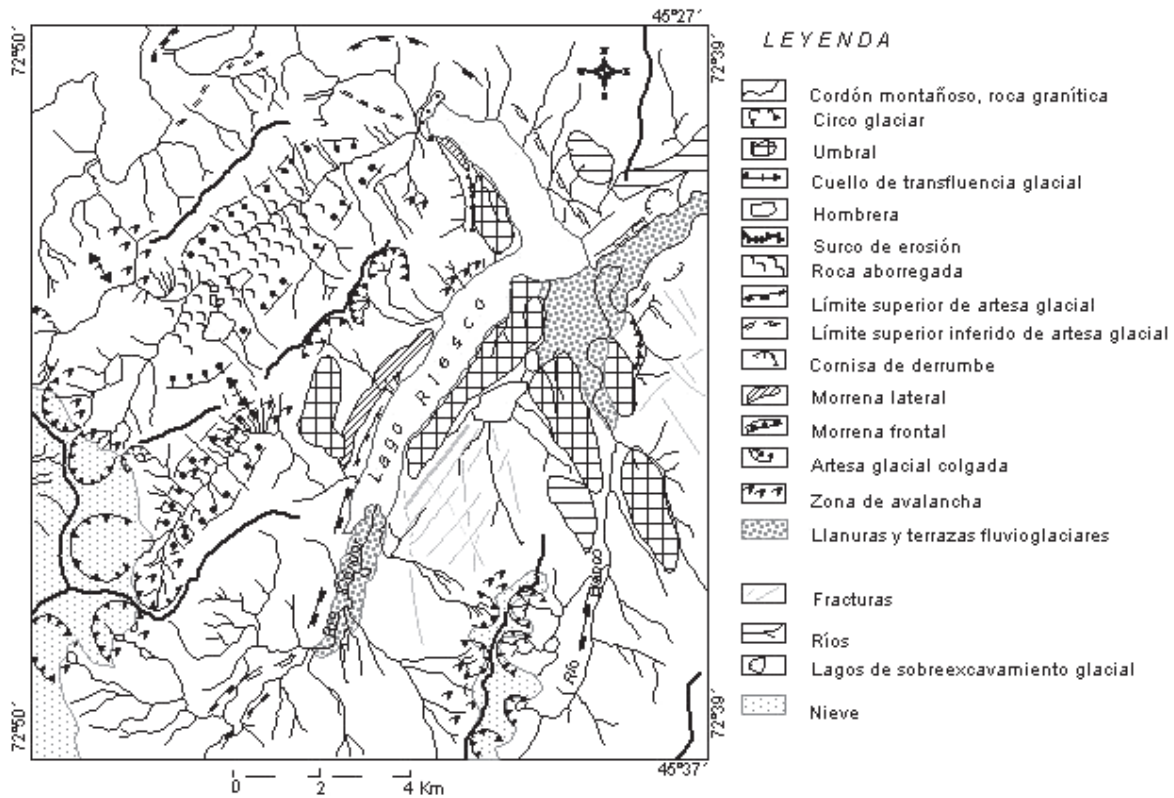

Fuente: Elaboración propia. 
Figura № 11

LA CAPTURA DEL LAGO ATRAVESADO

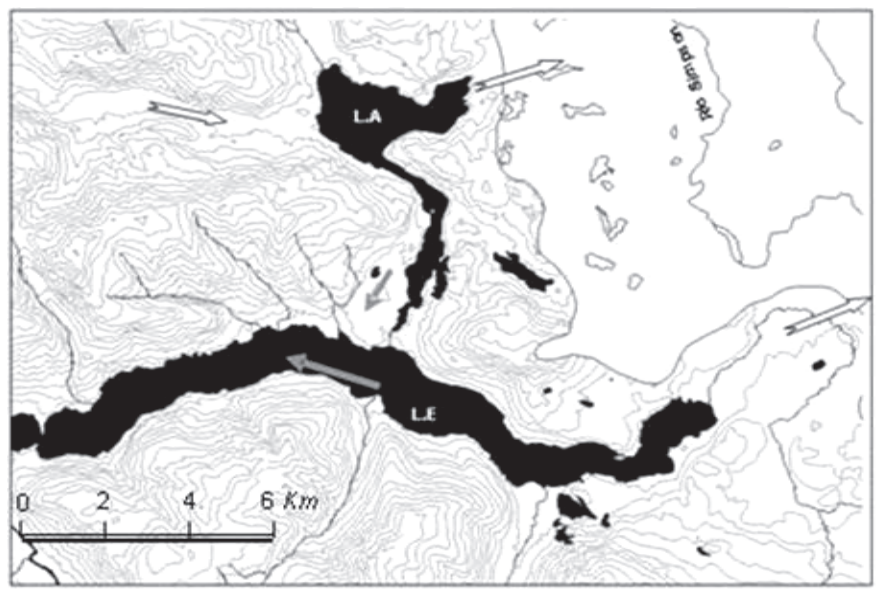

$\Longrightarrow$ Dirección del paleodrenaje pleistocénico

$\rightarrow$ Dirección del drenaje actual. L.A. Lago Atravesado; L.E. Elizalde; C. E. cuenca Extraandina

Fuente: Elaboración propia.

Las capturas descritas tienen 2 factores en común: se localizan en valles que fueron ocupados por potentes lenguas glaciales ( 1.000 m) durante el Máximo Glaciar, los cuales, con excepción de la subcuenca del Riesco, drenaban hacia la Zona Extraandina. Por otra parte, el trazado geométrico de la red evidencia una zona densamente tectonizada por fallas y algunas de las capturas tienen relación con estos lineamientos.

\section{La influencia de la tectónica}

Como se ha señalado precedentemente, la cuenca del río Blanco se emplaza en el extremo S de la Zona de Falla Liquiñe-Ofqui (ZFLO). Numerosos autores han estudiado la tectónica reciente caracterizada tanto por la transcurrencia destral como por altas tasas de alzamiento durante el Holoceno, que registra el sector (Cembrano et al., 2000; Hervé, 1976; Tassara, 2003).

La dinámica de esta estructura cortical controla la formación de las grandes morfoestructuras y el trazado y orientación de la red hidrográfica. En la Figura № 12 se reco-

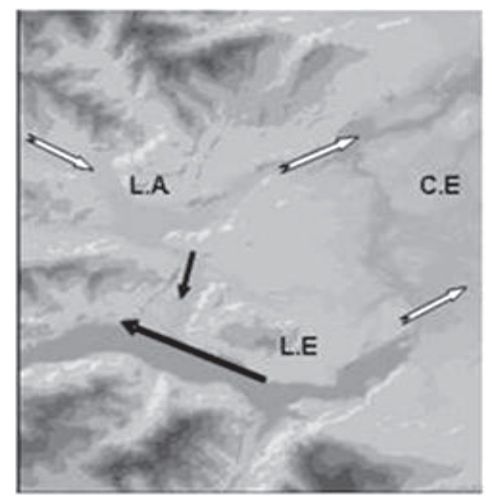

L.A. Lago Atravesad o; L.E. Elizalde; C. E. cuenca Extraandina nocen para el área 4 lineamientos principales: N-S, NE-SW, E-W y NW-SE, asociados a la geometría del complejo Liquiñe-Ofqui, descrito por Cembrano et al. (2000), a los cuales se adapta la red hidrográfica. De estos, el $47,12 \%$ tiene tendencia NE-SW y el $37,37 \%$ NW-SE. De los cuatro lineamientos, 3 están trabajados por erosión glaciar, en tanto que existen algunos lineamientos de dirección NNW en el margen oriental, no erosionados por el hielo, por lo que se estima que corresponden a un evento de deformación de edad Postglaciar. Las estructuras monoclinales son extremadamente corrientes; en la cobertura mesozoica y cenozoica tienen rumbo $\mathrm{N}-\mathrm{S}$ y muchas de ellas se inclinan hacia el bloque oriental, facilitando la desconexión del drenaje entre la precordiIlera y la Cuenca Extraandina oriental.

Las capturas de las subcuencas Elizalde y Quetro podrían estar relacionadas con estos movimientos tectónicos. En efecto, el valle del río Quetro presenta una fuerte ruptura de pendiente cuando su eje corta aproximadamente el meridiano $72^{\circ} 22^{\prime} \mathrm{W}$, lo que coincide con una línea de falla de orientación 

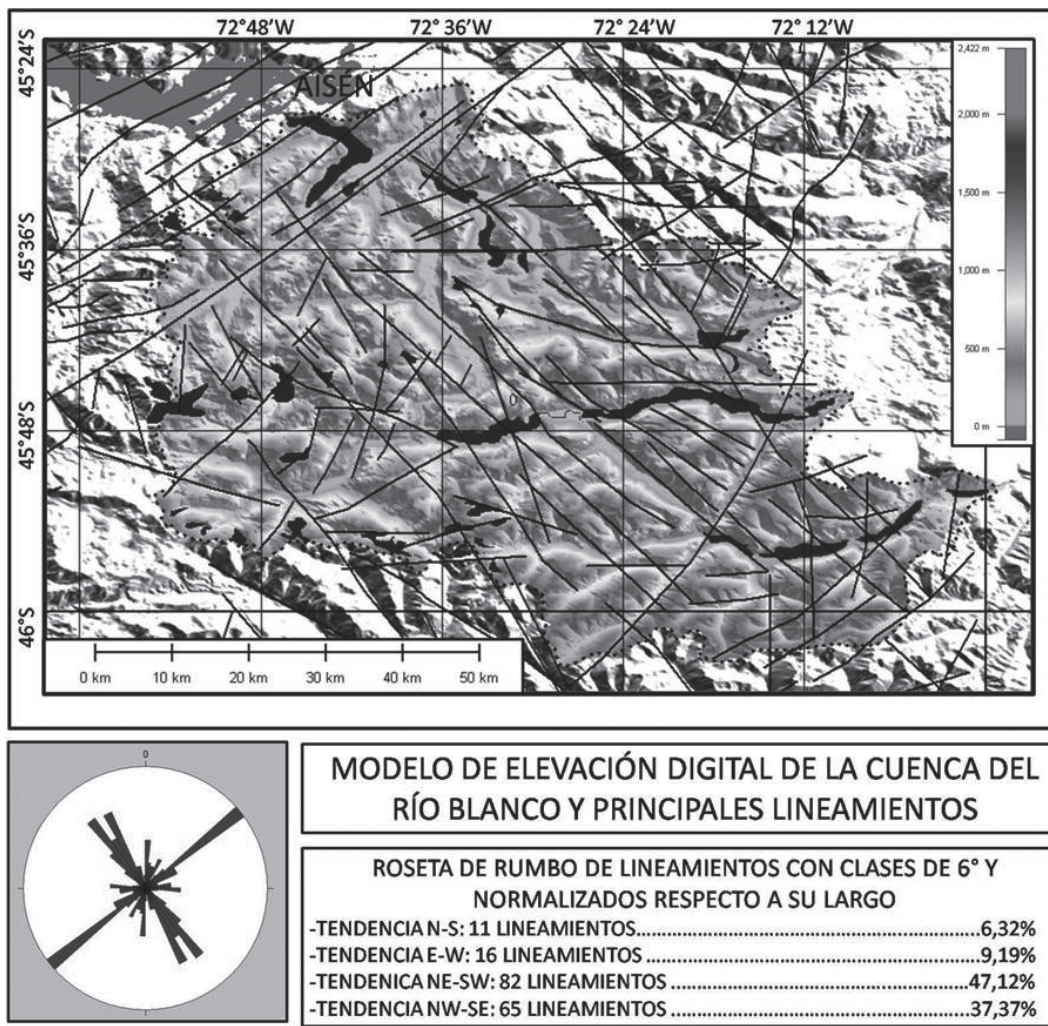

MODELO DE ELEVACIÓN DIGITAL DE LA CUENCA DEL RÍO BLANCO Y PRINCIPALES LINEAMIENTOS

\begin{tabular}{|c|}
\hline ROSETA DE RUMBO DE LINEAMIENTOS CON CLASES DE $6^{\circ} \mathrm{Y}$ \\
\hline NORMALIZADOS RESPECTO A SU LARGO \\
\hline -TENDENCIAN-S: 11 UNEAMIENTOS \\
\hline -TENDENCIA E-W: 16 LINEAMIENTOS \\
\hline -TENDENICA NE-SW: 82 LINEAMIENTOS \\
\hline 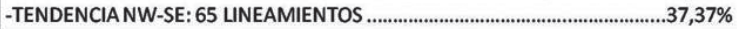 \\
\hline
\end{tabular}

Fuente: Elaboración propia.

NW-SE que se prosigue al sur y atraviesa toda la cuenca (Figura № 12). Hacia el este de la línea de falla, el fondo de valle se eleva, lo que puede haber facilitado la desviación del drenaje de este curso fluvial hacia el lago Elizalde.

Cembrano et al. (1996) consignan que el alzamiento tectónico estaría además potenciado por el rebote glacioisostático, lo que habría contribuido a una rápida erosión vertical de los ríos durante el periodo postglacial. Hervé y Ota (1993) han documentado para el Holoceno levantamientos de más de $3 \mathrm{~mm} / \mathrm{año}$ al interior de la zona de la ZFLO.

\section{El control morfoclimático de las capturas}

Artesas glaciales con desniveles topográficos de 500 a 1.000 m, algunas de ellas ocupadas por lagos de sobreexcavamiento glacial o por lagos de represa morrénica, prueban la intensa erosión glacial en el área investigada. La profundidad y orientación de los valles y el pulido glacial que cubre las paredes de estos, permite señalar que aquí se formó durante el Pleistoceno un vasto Campo de Hielo, con centro en los cerros Hudson y Castillo. Los glaciares rellenaron todas las depresiones topográficas con potencias de más de 1.000 m, durante el máximo avance de la última glaciación, desbordando hacia la Cuenca Extrandina de Coyhaique (Figura № 3).

Una datación absoluta realizada en la morrena frontal del lago Elizalde arroja una edad posterior a 9.370 BP. Relieves morrénicos similares se encuentran en los frentes de Ios lagos La Paloma y Atravesado, lo que permite estimar que a inicios del Holoceno 
las lenguas glaciares alcanzaban el borde oriental de la precordillera y el drenaje fluvioglacial aún se realizaba hacia el valle del Simpson, ubicado al E (Mardones y Jara, 2006). Por otra parte, otra morrena localizada en el fondo de valle del río Quetro en las proximidades del lago Portales, se dispone sobre depósitos lacustres que han sido datados de 2.250 BP. Considerando esta represa morrénica y glacial, se asume que durante el Holoceno tardío el río Blanco aún no era utilizado como nivel de base por el río Quetro. De este análisis se concluye que el patrón de drenaje de la actual cuenca del río Blanco se habría configurado hace aproximadamente 2.000 años.

Lamy et al. (2004) han demostrado la alta vulnerabilidad de este dominio a los cambios climáticos globales. La respuesta de los glaciares al calentamiento tardiglacial habría sido rápida, produciéndose la transformación del Campo de Hielo, aproximadamente en 3.000 años. El modelado glaciar del área indica que, tal como ocurre en el presente en el Campo de Hielo Norte (Glasser y Janson, 2005) donde sistemas de flujos controlados topográficamente generan un patrón de rápida deglaciación, procesos similares pudieron inducir una disminución acelerada del espesor y extensión del Campo de Hielo que ocupó la cuenca del río Blanco, primero en el Tardiglaciar y luego en el Postglaciar. Este mecanismo pudo forzar una fragmentación del Campo de Hielo, lo que habría generado cambios en la dirección de los patrones de descarga y una migración hacia el $\mathrm{W}$ de la divisoria de aguas.

A esto se agregan dos factores que contribuyeron a la formación de la red hidrográfica actual: por una parte, el mayor sobreexcavamiento y profundidad que presentaban los valles que drenan hacia el $\mathrm{W}$ antes de ser rellenados por el hielo, y en segundo lugar, la depositación de grandes conos de deyección que fueron construidos en el fondo de las artesas glaciales en la medida que progresaba la deglaciación. Estos dos factores fueron fundamentales en la captura de la red hidrográfica hacia el $W$ y su desconexión de la Cuenca Extraandina. Es el caso del río Diablito, que construye su cono en el interfluvio entre los valles del Quetro y del lago Atravesado (Figura № 3).

\section{Discusión}

Las paleorredes hidrográficas puestas en evidencia en la cuenca del río Blanco y su comparación con el actual sistema de drenaje sugieren modificaciones de la dirección del escurrimiento relacionadas principalmente con factores morfoclimáticos y tectónicos. La morfometría de la red hidrográfica muestra irregularidades en la razón de bifurcación, relación de longitud de cauce, pendiente de cauces y curva hipsométrica, que podrían indicar un rejuvenecimiento en el ciclo erosivo producido por deformaciones tectónicas recientes y/o descenso del nivel de base postglacial.

El efecto de un solevantamiento depende de la capacidad del sistema continental para absorber los cambios mediante una respuesta erosiva eficaz vertiente/ribera (Loget, 2005). La relación entre el tiempo durante el cual el solevantamiento perdura y el tiempo de respuesta de la cuenca, regula los procesos de erosión. Si el solevantamiento tectónico es más lento que el tiempo de respuesta, el paisaje conserva su morfología; en cambio una orogénesis activa y solevantamientos tectónicos rápidos pueden provocar cambios importantes en la dirección del drenaje por erosión regresiva de las cabeceras hidrográficas (Burbank \& Anderson, 2005). La presencia de valles de gran profundidad en la sección S y SE de la cuenca del río Blanco, en ausencia de contrastes litológicos (Figura № 2), podría indicar una caída abrupta del nivel de base a escala geológica. A la luz de los antecedentes ya descritos, tal morfología podría explicarse por una erosión vertical de los valles antes de ser cubiertos completamente por el hielo, como una respuesta del sistema sea a una perturbación morfoclimática (regresión marina contemporánea de la glaciación), sea a un solevantamiento tectónico de esa sección de la cuenca.

Líneas de drenaje de escasa longitud, fuerte densidad y pendientes longitudinales de gran declive, tal como se aprecian en el sector investigado, se asocian generalmente a flancos de cordilleras tectónicamente activas. Estudios realizados en los ríos Indo (Jorgensen et al., 1993) y en las cuencas que drenan la cordillera de Pamir (Burbank \& 
Anderson, 2005) demuestran que bruscos cambios en el patrón hidrográfico, de trazados con canales simples a trazados con canales meandriformes, estarían asociados a una tectónica activa que seccionaría ambas áreas e incluso muchos de estos se relacionarían con líneas de falla. Los mayores rangos de sinuosidad y el trazado meandriforme del cauce observado en el sector NW de la cuenca del río Blanco $(>2,7)$ podrían estar relacionados con un basculamiento tectónico en la misma dirección.

Burbank \& Anderson (2005) señalan que al combinarse fallas de rumbo y fallas normales o inversas, pueden desplazarse bloques generando pequeñas cuencas colapsadas que podrían desconectar canales de drenaje y generar capturas. Dorsey et al. (2006) estudian, mediante el análisis del perfil longitudinal de los tributarios, capturas producidas por fallas de rumbo en la zona de Falla de San Jacinto al S de California. Las fallas habrían generado un desequilibrio geomorfológico durante los 2 últimos millones de años induciendo una migración del punto de captura, con un retroceso estimado entre $12-44 \mathrm{~km} / \mathrm{m}$.a. El estudio de los perfiles longitudinales de los ríos Quetro y La Paloma en la cuenca del río Blanco, muestran rupturas de pendiente (knickpoint) que coinciden con bloques limitados por líneas de falla de dirección NW-SE para el primero y SW-NE para el segundo ( $\mathrm{Fi}$ gura № 12 ).

Forsythe \& Digmer (2000) a través de métodos estratigráficos estiman desplazamientos diferenciales de 15-20 m en los últimos 30.000 años y $2 \mathrm{~m}$ de subsidencia en los últimos siglos, cerca del istmo de Ofqui (Aysén) y control tectónico de la cuenca de drenaje de la bahía de San Quintín. Estos autores describen dos fallas activas, asociadas a la ZFLO, que se cortan en orientación NE y SW y transforman el drenaje en un estilo muy similar a lo observado en la cuenca del río Blanco.

En el estado actual de conocimientos, tampoco se pueden excluir los ajustes glacioisostáticos (Chevillote et al., 2005); aunque estimar cuantitativamente la influencia del rebote isostático postglacial en la organización de la red de drenaje es complejo y no está dentro de los objetivos de este trabajo.
Sería necesario combinar las variaciones del volumen de hielo, las diferentes densidades de las rocas y los volúmenes erosionados durante el periodo Glaciar y Postglaciar. Por otra parte, Lambeck \& Chapell (2001) han mostrado la gran variabilidad espacial que se registra en este parámetro a nivel mundial.

Las variaciones glacioeustáticas pueden ser un factor importante en la generación de capturas, particularmente por la rapidez de los cambios climáticos documentados para la Terminación I en la Región de Aysén (Lamy, 2004). Los rangos de sedimentación extraordinariamente altos (1 m/1.000 años) registrados especialmente en ambientes oceánicos, muestran que esta zona reaccionó muy sensiblemente a los cambios climáticos. Retrocesos rápidos del hielo e incrementos del nivel del mar se habrían producido particularmente entre el 18.00017.000 BP y entre 13.000-12.000 BP (Moreno, 2004). Estos cambios climáticos mileniales que se suceden durante el Tardi y Postglaciar habrían producido una rápida disminución del volumen de hielo, a un ritmo mayor que la capacidad de erosión de los ríos, lo que dificultó conservar la orientación del drenaje existente durante el Ultimo Máximo Glaciar.

Tampoco se descarta que la tectónica cosísmica pueda tener incidencia en la organización actual de la red. En Chiloé, al N de la zona de estudio, mediante datación de terrazas marinas, se han estimado tasas de alzamiento cosísmica holocena de hasta 10 $\mathrm{m} / 1.000$ años. Alzamiento que se incrementa de W (Hervé \& Ota, 1993).

Finalmente, la gran profundidad de los valles y la adaptación de las artesas glaciales a los lineamientos tectónicos permiten postular que la tectónica preglaciar controla el trazado de la red hidrográfica y que los valles principales se han modelado por lo menos antes de la última glaciación. Durante la última fase glaciar el nivel del mar descendió a nivel global a lo menos $100 \mathrm{~m}$ (Lambeck \& Chappell, 2001); si se aplica lo expresado por Loget (2005), en el sentido de que un descenso del nivel de base cualquiera sea su amplitud, puede detonar procesos de erosión vertical en los valles preexistentes, se dieron en este periodo las condicio- 
nes óptimas para la erosión regresiva y profundización de los valles en la cuenca del río Blanco.

La distribución de las formas de erosión y acumulación glacial en la cuenca confirman que durante el máximo avance del Estadio Isotópico Marino 4, la zona fue cubierta por un Campo de Hielo que rellenó los valles y transfluyó hacia la Zona Extraandina (cuenca del río Simpson), del mismo modo como ocurrió en la cuenca del lago General Carrera, al S del área investigada (Beltramone, 1991; Douglass et al., 2002). Por último, la rápida deglaciación expuso nuevamente a condiciones subaéreas el relieve cuyos rasgos más importantes habrían sido elaborados en un periodo anterior a la última glaciación. En este sentido, las verdaderas capturas se habrían producido durante la glaciación por la avulsión del hielo hacia el $\mathrm{E}$, mientras que durante el Holoceno se habrían restaurado las direcciones del drenaje dominantes en el último periodo Interglaciar, con excepción de la captura de la subcuenca del lago Elizalde donde habrían participado factores tectónicos.

\section{Conclusiones}

Se concluye que el patrón hidrográfico actual del río Blanco y particularmente las capturas son de origen Holoceno y estarían relacionadas principalmente con factores tectónicos y con la dinámica de deglaciación de la zona austral de Chile. Se calcula una edad aproximada de 2.000 años para esta red.

La cuenca presenta una red adaptada a lineamientos estructurales generados por un régimen de deformación asociado a la ZFLO, que ha actuado desde el Plioceno al actual. Las fallas preglaciares fueron trabajadas por las lenguas glaciares durante el Pleistoceno, y su influencia en la geomorfología y el drenaje ha sido continua durante el Holoceno.

La geomorfología muestra abundantes huellas de capturas del drenaje, que se explican por 3 factores: formación de un Campo de Hielo que rellena cuencas hidrográficas modeladas antes de la última glaciación, cuyas lenguas periféricas en el sector estudiado drenaban hacia la vertiente atlántica; lineamientos y solevantamientos tectónicos asociados a la ZFLO y deglaciación rápida postglacial, con un ritmo de disminución del volumen de hielo superior a la capacidad erosiva de los ríos, lo que favoreció la formación de capturas y la reorientación del escurrimiento fluvial hacia la vertiente pacífica.

* Se agradece la colaboración de la Sra. Lidia Esparza en la elaboración final de las figuras.

\section{Referencias bibliográficas}

APARICIO, F. J. Fundamentos de hidrología de superficie. 11aㅡ ed. México: Limusa Noriega Editores, 2003.

BELTRAMONE, C. Estratigrafía glacial del valle del río Mayo, provincia de Chubut, Argentina. En: Actas VI. Congreso Geológico Chileno. Antofagasta: Servicio Nacional de Geología y Minería, 1991, p. 58-61.

BURBANK, D. \& ANDERSON, R. Tectonic Geomorphology. 4 $4^{\mathrm{a}}$ ed. Malden: Editorial Blackwell Science, 2005.

CEMBRANO, J.; HERVE, F. \& LAVENU, A. The Liquiñe Ofqui Fault Zone: a long-lived intra-arc fault system in southern Chile. Tectonophysics, 1996, Vol. 259, p. 55 - 66.

CEMBRANO, J.; SCHERMER, E.; LAVENU, A. \& SANHUEZA, A. Contrasting nature of deformation along an intra-arc shear zone, the Liquiñe-Ofqui fault zone, Southern Chilean Andes. Tectonophysics, 2000, Vol. 319, p. 129-149.

CEMBRANO, J.; LAVENU, A.; REYNOLDS, P.; ARANCIBIA, G.; LÓPEZ, G. \& SANHUEZA, A. Late Cenozoic transpressional ductile deformation north of the NazcaSouth America-Antartica triple junction. Tectonophysics, 2002, Vol. 354, p. 289-314.

CHEVILLOTE, V.; DOUILLETE, P.; GABIOCH, G. LAFOY, Y.; LAGABRIELLE, Y. \& MAURIZOT, P. Evolution géomorphologique de I'avant-pays du Sud-Ouest de la NouveIle-Calédonie durant les derniers cycles glaciaires. C. R. Geoscience, 2005, № 337, p. 695-701. 
COX, R.T. Análisis of drainage-basin symetry as a rapide technique to identify areas of possible Quaternary tilt-block tectonics: an example from the Mississipi embayement. Geological Society of America Bulletin, 1994, Vol. 104, p. 571-581.

DE LA CRUZ, R.; SUÁREZ, M.; BELMAR, M.; QUIROZ, D. \& BELL, M. Carta Geológica de Chile. Área Coyhaique-Balmaceda, Región Aisén del General Carlos Ibáñez del Campo. Santiago: Servicio Nacional de Geología y Minería, 2003, № 80.

DE PEDRAZA, J. Geomorfología: principios, métodos y aplicaciones. $1^{\underline{a}}$ ed. Madrid: Editorial Rueda, 1996.

DORSEY, R. \& ROERING, J. Quaternary landscape evolution in the San Jacinto fault zone, Ranges of Southern California: transient response to the strike-slip fault initiation. Geomorphology, 2006, Vol. 73, Issues 1-2, p.16-32.

DOUGLASS, D. C.; KAPLAN, M. R.; SINGER, B. S. \& MICKELSON, D. A low gradient outlet glacier of the Patagonian Ice Cap at Lago Buenos Aires, Argentina, during the Last Glacial Maximum. Geological Society of America, Abstracts whit Programs, 2002, Vol. 34, № 6, p. 506.

FORSYTHE, R. D. \& DIGMER, J. A. Neotectonic observations from the southern terminus of the Liquiñe-Ofqui fault, isthmus of Ofqui. En: Actas IX Congreso Geológico Chileno. Simposio Nacional. Puerto Varas: Servicio Nacional de Minería y Geología, 2000, Vol. 2, № 2, p. 205-209.

FUENZALIDA, H. Climatología. En: CORFO. Geografía Económica de Chile. Primer Apéndice. Santiago: Corporación de Fomento de la Producción, 1966, p. 31-44.

GLASSER, N. F. \& JANSSON, K. N. Fast flowing outlet glaciers of the Last Glacial Maximum Patagonian Icefield. Quaternary Research, 2005, Vol. 63, № 2, p. 206-211.

HERVÉ, M. Estudio geológico de la Falla Liquiñe-Reloncaví en el área de Liquiñe: antecedentes de un movimiento transcurrente (Provincia de Valdivia). En: Actas Congreso Geológico
Chileno. Santiago: Servicio Nacional de Minería y Geología, 1976, Vol. 1, p. B39-B56.

HERVÉ, F. \& THIELE, R. Estado de conocimiento de las megafalla en Chile y su significado tectónico, Megafaults in Chile: a review. Comunicaciones, Universidad de Chile, Departamento de Geología, 1987, № 38, p. 67-91.

HERVÉ, F.; DRAKE, R.; PANKHURST, R. J.; BECK, J. R. \& MPODOZIS, C. Granite generation and rapid unroofing related to strike-slip faulting, Aysén, Chile. Earth and Planetary Science Letters, 1993, Vol. 120, № 34, p. 375-386.

HERVÉ, F. \&. OTA, Y. Fast Holocene uplift rates at the Andes of Chiloé, Southern Chile. Revista Geológica de Chile, 1993, Vol. 20, № 1, p. 15-23.

HERVÉ, F.; PANKHURST, R.; DRAKE, R. \& BECK, M. Pillow metabasalts in a mid - Tertiary extensional basin adjacent to the Liquiñe - Ofqui zone: the Isla Magdalena Area, Aysén, Chile. Journal of South American Earth Sciences, 1995, Vol. 8, №. 1, p. 33-40.

HORTON, R. E. Erosional Development of streams and their drainage basins; hidrophisical approach to quantitative morphology. Geological Society of America Bulletin, 1945, Vol. 56, p. 275-376.

JORGENSEN, D. W.; HARVEY, M. D.; SCHUMM, S. A. \& FLAM, L. Morphology and dynamics of the Indus River: Implications for the Mohen Jo Daro site. En: SHRODER, J. F. Geomorphology and the Quaternary. London: Ed. Himalaya to the Sea: Geology, 1993, p. 288-326.

LAMBECK; K. \& CHAPPELL, J. Sea level change through the last glacial cycle. Science, 2001, Vol. 292, p. 679-686.

LAMY, F.; KAISER, J.; NINNEMANN, U.; HEBBELN, D; ARZ, H. \& STONER, J. Antartic timing of surface water off Chile and $\mathrm{Pa}-$ tagonian Ice Sheet response. Science, 2004, Vol. 304, p. 1959-1962.

LOGET, N. Dynamique de l'érosion fluviatile consécutive à une chute du niveau de 
base. L'exemple de la Crise de Salinité Messinienne. Thèse de Doctorat. Rennes: Université de Rennes I, Editions de Géosciences Rennes, 2005.

MARDONES, M. y JARA, C. Evolución Geomorfológica del Pleistoceno reciente $y$ Holoceno en la cuenca del río Blanco, XI Región de Aysén. En: Actas del XXVII. Congreso Nacional y XII Congreso Internacional de Geografía. Concepción: Sociedad. Chilena de Ciencias Geográficas - Universidad de Concepción, 2006.

MATHER, A. E. Impact of headwater river capture on alluvial system development: an example from the Plio-Pleistocene of the Sorbas Basin, SE Spain. Journal of the Geological Society. 2000, Vol. 157, № 5, p. 957-966.

MINISTERIO DEL MEDIO AMBIENTE. Guía para la elaboración de estudios del medio físico. Contenido y metodología. $3^{a}$ ed. Madrid: Secretaría General del Medio Ambiente. Serie Monografías, 1998.

MOLNAR, P. \& ENGLAND, P. Late Cenozoic uplift of mountain ranges and global climatic change: chicken or egg? Nature, 1990, Vol. 346, p. 29-34.

MORENO, P. Millennial scale climate variability in northwest Patagonia over de last $15000 y r$. Journal of Quaternary Science, 2004, Vol. 19, № 1, p. 35-47.

NIEMEYER, H.; SKARMETA, R.; FUENZALIDA, R. \&. ESPINOZA, W. Carta Geológica de Chile. Hojas Península de Taitao y Puerto Aysén, Región de Aysén, № 60 - 61. Santiago: Servicio Nacional de Geología y Minería, 1984.

OWENS, P. \& SLAYMAKER, O. (eds.). Mountain Geomorphology. London: Owens \& Slaymaker, 2004.

PARADA, M. A.; LAHSEN, A. \& PALACIOS, C. Magmatic evolution of the eastern part of the Chilean Patagonia (Aysén Region): geochronological and geochemical constra- ints. Third Symposium Internacional sur la Géodynamique Andine (ISAG). Saint Malo: Editions de l'Orstom, 1996, p. 617-620.

ROMERO, H. Geografía de los climas. Tomo XI. En: IGM. Geografía de Chile. Santiago: Instituto Geográfico Militar, 1985.

SERNAGEOMIN, 2003. Mapa Geológico de Chile: versión digital. Santiago: Servicio Nacional de Geología y Minería, Publicación Geológica Digital № 4 (CD-ROM, versión1.0), 2003.

SKARMETA, J. Carta Geológica de Chile. Región Continental de Aysén entre el Lago General Carrera y la Cordillera Castillo, № 29, escala 1:250.000. Santiago: Instituto de Investigaciones Geológicas, 1978.

SINGH, V. P. Elementary hidrology. New Jersey: Prentice Hall, 1992.

STRAHLER, A. N. Quantitative geomorphology of drainage basins and channel networks. Handbook of Applied Hydrology, 1964, Section 4 - I, p. 39-76.

TASSARA, A. y YÁÑEZ, G. Relación entre el espesor elástico de la litósfera y la segmentación tectónica del margen andino (15 - 47ํㅗ S). Revista Geológica de Chile, 2003, Vol. 30, № 2, p. 159-186.

TEBBENS, S; CANDE, S. C.; KOVACS, L.; PARRA, C.; LABRECQUE, J. L. \& VERGARA, $H$. The Chile ridge: a tectonic framework. Journal of Geophysical Research, 1997, Vol. VI, p. 12.35-12.59.

VAN HEIJST, M. \& POSTMA, G. Fluvial response to sea-level changes: a quantitative analogue, experimental approach. Basin Research, 2001, Vol. 13, № 3, p. 269-292.

WIPPLE, K. X. \& TUCKER, G. E. Dynamics of the stream-power river incision model: implications for height limits of mountain ranges, landscape response timescales and research needs. Journal of Geophysical Research, 1999, Vol. 104, p. 17,66117,674 . 